\title{
Central Corneal Thickness Is Highly Heritable: The Twin Eye Studies
}

\author{
Tze'Yo Toh, ${ }^{1,2}$ S. H. Melissa Liew, ${ }^{2,3}$ Jane R. MacKinnon, ${ }^{4}$ Alex W. Hewitt, ${ }^{5,6}$ \\ Johan L. Poulsen, ${ }^{5,6}$ Tim D. Spector, ${ }^{3}$ Clare E. Gilbert, ${ }^{7}$ Jamie E Craig, ${ }^{8}$ \\ Christopher J. Hammond, ${ }^{3}$ and David A. Mackey ${ }^{1,5,6}$
}

Purpose. A classic twin study was performed to determine the heritability of central corneal thickness (CCT), an important parameter in glaucoma assessment.

Methods. The concordance of CCT between monozygotic (MZ) and dizygotic (DZ) twins was compared. A total of 256 twin pairs (131 MZ and $125 \mathrm{DZ}$ ) were recruited from three centers: the Twin Eye Study in Tasmania, the Brisbane Adolescent Twin Study, and the Twins U.K. Adult Registry held at St. Thomas' Hospital in London. As part of an extensive ophthalmic evaluation, CCT was measured by ultrasound pachymetry. Structural equation modeling with the Mx program (Department of Psychiatry, Medical College of Virginia, Richmond, VA) was used to determine the heritability of CCT.

Results. The mean age of subjects was 38 years (range, $8-81$ ). The mean CCT of all eyes examined was $544.5 \pm 37.3 \mu \mathrm{m}$ (SD). The CCT measurements correlated more highly in MZ twins than in DZ twins, with intraclass correlation coefficients of 0.95 and 0.52 , respectively, suggesting a strong genetic influence. A model of additive genetic and unique environmental effects provided the best fit, yielding a heritability of 0.95 (95\% confidence interval [CI], 0.93-0.96) with the remaining variation being attributable to unique environmental factors.

Conclusions. In this study of Australian and U.K. twins, genetic factors were shown to be of major importance in CCT, with a

From the ${ }^{1}$ University of Tasmania, The Eye Hospital, Launceston, Australia; the ${ }^{3}$ Twin Research and Genetic Epidemiology Unit, St. Thomas' Hospital, London, United Kingdom; the ${ }^{4}$ Department of Ophthalmology, Raigmore Hospital, Inverness, United Kingdom; the ${ }^{5}$ Centre for Eye Research Australia, University of Melbourne, Melbourne Australia; the ${ }^{6}$ Department of Ophthalmology, Royal Victorian Eye and Ear Hospital, Melbourne, Australia; the ${ }^{7}$ International Centre for Eye Health, London School of Hygiene and Tropical Medicine, London, United Kingdom; and the ${ }^{8}$ Department of Ophthalmology, Flinders Medical Centre, Adelaide, Australia.

${ }^{2}$ Contributed equally to the work and therefore should be considered equivalent authors.

Supported in Australia by the Clifford Craig Medical Research Trust, the Ophthalmic Research Institute of Australia, Glaucoma Australia, the Eye, Ear Nose Throat Research Institute, and the Jack Brockhoff Foundation and in the United Kingdom by the Wellcome Trust. The St. Thomas' U.K. Adult Twin Registry also receives support from the Arthritis Research Campaign, the British Heart Foundation, and the Chronic Disease Research Foundation.

Submitted for publication December 19, 2004; revised February 27 and March 20, 2005; accepted March 31, 2005.

Disclosure: T.-Y. Toh, None; S.H.M. Liew, None; J.R. MacKinnon, None; A.W. Hewitt, None; J.L. Poulsen, None; T.D. Spector, None; C.E. Gilbert, None; J.E. Craig, None; C.J. Hammond, None; D.A. Mackey, None

The publication costs of this article were defrayed in part by page charge payment. This article must therefore be marked "advertisement" in accordance with 18 U.S.C. $\$ 1734$ solely to indicate this fact

Corresponding author: Christopher J. Hammond, Twin Research and Genetic Epidemiology Unit, St. Thomas' Hospital, London SE1 7EH, UK; chammond@btopenworld.com. heritability of 0.95. (Invest Ophthalmol Vis Sci. 2005;46: 3718-3722) DOI:10.1167/iovs.04-1497

$\mathrm{C}$ entral corneal thickness (CCT) has been proposed recently as an important factor in glaucoma diagnosis and management, and as such the analysis of determinants of CCT is of interest. Given the hereditary nature of primary open angle glaucoma (POAG), future mutation screening may identify susceptible individuals, who could be closely reviewed clinically, allowing intervention before disease progression. At present, mutations in only three genes (myocilin, optineurin, and WDR-36;) have been shown to cause POAG, and each accounts for only a small proportion of cases. ${ }^{1-3}$ For a complex heterogeneous disease such as POAG, the study of an intermediate phenotype or significant confounder such as CCT may facilitate identification of further glaucoma-related genes.

Elevated intraocular pressure (IOP) is an important risk factor for POAG. Reducing IOP is associated with a significant reduction in the rate of visual field progression. ${ }^{4}$ Goldmann applanation tonometry (GAT) is accepted as the gold standard for IOP measurements. Although GAT assumes a CCT of 500 $\mu \mathrm{m}$, it has been shown to reflect most accurately the true IOP when the CCT is $520 \mu \mathrm{m} .{ }^{5}$ However, CCT varies greatly in the normal population. ${ }^{6}$ Consequently, CCT is a confounder when performing GAT, with underestimation of IOP in eyes with thin corneas and overestimation in eyes with thick corneas. ${ }^{5}$ The Ocular Hypertension Treatment Study (OHTS) demonstrated that CCT significantly influences the likelihood of conversion from ocular hypertension to glaucoma. ${ }^{7}$ Thinner CCT has been associated with advanced glaucoma, although the mechanism has not yet been determined. ${ }^{8}$ CCT has been reported to be associated with glaucoma progression, although there is still debate about the issue. ${ }^{9}$

A hereditary basis for CCT was suggested in 1978 through a population-based familial aggregation study of Greenland Eskimos, which estimated CCT heritability to be between 0.6 and $0.7 .^{10}$ Reduced CCT has been associated with some genetic diseases such as congenital glaucoma, ${ }^{11}$ osteogenesis imperfecta, ${ }^{12}$ Down syndrome, ${ }^{13}$ X-linked megalocornea, ${ }^{14}$ keratoconus, ${ }^{15}$ Marfan syndrome, ${ }^{16}$ and Ehlers-Danlos syndrome, ${ }^{17}$ whereas increased CCT has been found in patients with congenital aniridia. $^{18}$

Twin studies are an excellent method of studying the relative importance of genetic and environmental influences on a phenotype. ${ }^{19}$ Such investigations are based on the assumption that siblings share the same environmental influences, yet monozygotic (MZ) twins have identical genes and dizygotic (DZ) twins have, on average, only half of their segregating genes in common. Thus, a greater concordance in MZ twins than in DZ twins may be attributable to genetic factors.

We conducted a classic twin study to determine the heritability of CCT in a general population. Using modern genetic modeling techniques, we compared the covariance of CCT between $\mathrm{MZ}$ and $\mathrm{DZ}$ twins. 


\section{Methods}

\section{Subject Recruitment}

Twins were recruited for an ocular examination from three registries. Australian twins were recruited from the Twin Eye Study in Tasmania (TEST) and the Brisbane Adolescent Twin Study. ${ }^{20}$ U.K. twin pairs were recruited from the Twins U.K. Adult Registry held at St. Thomas' Hospital in London. All three centers recruited subjects from the general population, through local and national media campaigns. In Australia, more than 30,000 sets of twins have volunteered to be on the Australian twin registry, many nominated by their parents over a decade ago. ${ }^{21}$ We sent invitations to all twins in Tasmania (over 1000 eligible pairs) to participate in an extensive eye examination. In Brisbane, $502 \mathrm{DZ}$ pairs of adolescent twins have been involved in previous studies, including a genome-wide scan analysis of eye color. ${ }^{22}$ There may be bias of people with a personal or family history of eye disease agreeing to participate, the same for every population based study. More "community-minded" people are also more likely to participate. We evaluated the first 123 pairs in Tasmania and the first 12 pairs in Brisbane who had undergone pachymetry.

U.K. twins were already volunteers on the twin registry for reasons other than eye studies and were subsequently invited to have pachymetry performed either as a result of agreeing to come up for a "twin day" to meet other twins and undergo a variety of tests, or as part of a macular pigment study involving healthy female volunteers aged 18 to 50 years. In both cases, subjects were unaware of the test and its connection to glaucoma. They originally volunteered in response to appeals for twin volunteers aged more than 10 years. The Twin Research Unit had issued press releases with publications and asked for volunteers for original studies related to osteoporosis and osteoarthritis, and so only women were recruited initially, via TV, radio, magazines, newspapers. There are, at present, 8000 pairs of twins in the Twins U.K. database, and the volunteers for this study were more likely to live near London than is the average person, but did not differ in other respects from the overall group (for example, mean age).

Research adhered to the tenets of the Declaration of Helsinki, after local ethics committee approval and informed consents were obtained. To minimize ascertainment bias, participants were unaware of the pachymetry test when they volunteered.

\section{Clinical Examination}

In all subjects, topical anesthetic drops (either $0.4 \%$ oxybuprocaine or $0.5 \%$ proxymetacaine) were administered to both eyes 1 minute before CCT measurement. For the Australian twins, CCT was measured with a pachymeter (model SP 2000; Tomey Corp., Nagoya, Japan). An average of five consecutive measurements were recorded in each eye. An ultrasound pachymeter (model 500; DGH Technology, Inc., Scarsdale, NY) was used to measure the CCT of the U.K. twins, and three consecutive measurements were taken in each eye. Twin pairs were measured at the same time of day to avoid bias related to diurnal variation. A detailed ocular history and ocular examination was performed on all twins, and subjects with anterior segment disease or previous refractive surgery were excluded from the study. Two pairs were excluded from the U.K. study due to previous photorefractive keratectomy for myopia in one of the pair.

\section{Determination of Zygosity}

The zygosity of the Australian twins was determined by DNA analysis of short tandem-repeat (STR) polymorphisms, whereas in the United Kingdom, zygosity was determined by a standardized questionnaire. ${ }^{23}$ In cases in which there was still any doubt concerning zygosity, it was confirmed by DNA analysis of polymorphisms (AmpF1 STR Profiler kit; Applied Biosystems, Inc. [ABI], Foster City, CA). The questionnaire has been found to be approximately $95 \%$ accurate in determining zygosi$\mathrm{ty}^{23,24}$ compared with STR polymorphisms which has an accuracy of greater than $99 \% .{ }^{25}$ In U.K. twins, $42.5 \%$ underwent STR polymorphism analysis to confirm zygosity.

\section{Data Analysis}

The CCT for each subject was calculated as the mean CCT for the two eyes. Before pooling, results from the Australian and U.K. groups were analyzed separately, investigating for the presence of geographic differences.

Possible measurement error of CCT may occur when readings are not performed perpendicular to the cornea (and the CCT measurement will be too high). Lowest measurements may be more accurate than the mean. There was a $1 \%$ to $3 \%(5-15 \mu \mathrm{m})$ difference between the lowest CCT and the mean CCT. However, the purpose of this study was not to establish the true mean population CCT, but to compare variance within twin pairs. There should be no significant bias if standardized measurement techniques are used, such as the mean CCT. Reanalysis of the U.K. twins with the lowest CCT reading of both eyes did not alter the twin correlations found with the mean.

Maximum likelihood modeling was conducted to estimate heritability. ${ }^{26}$ In summary, the covariance within the MZ group was compared with that of the DZ twins. The observed phenotypic variance was defined by additive (A) or dominant (D) genetic components in conjunction with common (C) or unique (E) environmental components. Bias introduced through measurement error was incorporated into the latter component (E). Heritability, the proportion of variation attributable to genetic factors, was determined by the ratio of the variance due to genetic effects to the total phenotypic variance $\left(b^{2}=\right.$ $[\mathrm{A}+\mathrm{D}] /[\mathrm{A}+\mathrm{D}+\mathrm{C}+\mathrm{E}])$. A significant deterioration in the fit, as determined by the hierarchic $\chi^{2}$ test, implied the component was significant and should not be removed from the final model. The Akaike Information Criterion (AIC) was used to determine the best fitting model, by describing the best goodness-of-fit combined with fewest latent variables. The model with the lowest AIC suggested the best fit.

Data management and statistical tests were performed with a computerized statistics package (STATA, ver. 8 SE; Stata Corp., College Station, TX). Genetic modeling was conducted using Mx (Department of Psychiatry, Medical College of Virginia, Richmond, VA). Data are expressed as the mean $\pm \mathrm{SD}$.

TABLE 1. Summary of Intraclass Correlations between MZ and DZ Twin Pairs from the Two Study Populations

\begin{tabular}{|c|c|c|c|c|c|c|}
\hline & \multicolumn{2}{|c|}{ Total } & \multicolumn{2}{|c|}{ U.K. Twins } & \multicolumn{2}{|c|}{ Australian Twins } \\
\hline & $\mathbf{M Z}$ & $\mathbf{D Z}$ & MZ & $\mathbf{D Z}$ & MZ & $\mathbf{D Z}$ \\
\hline Number & 262 & 250 & 128 & 114 & 134 & 136 \\
\hline Mean age (SD) (y) & $40.6(15.2)$ & $35.4(13.3)$ & $43(10.6)$ & $41.5(9)$ & $38(18.3)$ & $30.3(14.2)$ \\
\hline & \multicolumn{2}{|c|}{$38(15)$} & \multicolumn{2}{|c|}{$43(11)$} & \multicolumn{2}{|c|}{$34(17)$} \\
\hline Mean CCT (SD) $(\mu \mathrm{m})$ & $544(37)$ & $547(37)$ & $538(32)$ & $543(33)$ & $546(41)$ & $546(38)$ \\
\hline Intraclass correlation of mean CCT & 0.95 & 0.52 & 0.94 & 0.53 & 0.96 & 0.52 \\
\hline
\end{tabular}




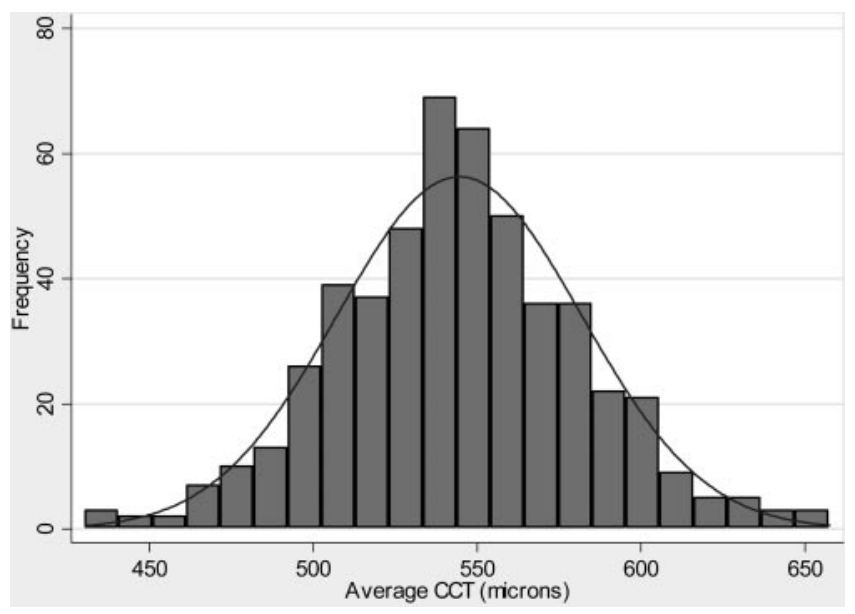

FigURE 1. Distribution of CCT.

\section{Results}

Two hundred fifty-six unselected twin pairs (131 MZ, $125 \mathrm{DZ}$ ) were recruited from Australia and the United Kingdom. All were white. One hundred eighty-eight pairs were same-sex female twins (117 U.K., 71 Australian), 32 pairs were same-sex male twins ( 3 U.K., 29 Australian), and 36 pairs were mixedsex twins ( 1 U.K., 35 Australian). The mean age of all subjects was $38 \pm 15$ years (range, $8-81$ ). The Australian twins were on average younger than the U.K. twins (mean age, $34 \pm 17$ and $43 \pm 11$ years, respectively). Demographic information is provided in Table 1.

The CCTs in all subjects studied were normally distributed (Fig. 1). The CCT for each subject's right and left eyes correlated highly (intraclass correlation coefficient: 0.97). Further analysis was performed using the mean CCT of both eyes for each subject. Analysis for each eye separately was similar (results not shown).

The mean CCT of all subjects was $544.5 \pm 37.3 \mu \mathrm{m}$. A weak negative correlation between CCT and age was identified ( $r=$ $-0.09, P=0.048)$. Given that this effect was small, age was not included in further analysis. There was no significant correlation of CCT with refractive error $(P=0.47)$.

Overall, there was no significant difference $(P=0.5$, unpaired $t$-test) in CCT between U.K. twin pairs $(543.1 \pm 32.6$ $\mu \mathrm{m})$ and Australian twin pairs $(545.6 \pm 40.9 \mu \mathrm{m})$. However, the CCT of U.K. MZ twins was significantly thinner than U.K. DZ twins (mean, $538 \pm 32$ for MZ and $549 \pm 33$ for DZ; $P=$ 0.02). In the Australian group there was no significant difference between the CCT of MZ and DZ twins $(P=0.78)$.

Male twins were found to have a mean CCT of $550 \pm 36.6$ $\mu \mathrm{m}$ and female twins had a mean CCT of $542 \pm 36.8 \mu \mathrm{m}$
(Table 2), which was not significantly different $(P=0.12$, unpaired $t$-test).

CCT correlated highly within MZ twin pairs (product moment correlation coefficient, 0.95; $r^{2}=0.9, P<0.001$ ), whereas the correlation of CCTs in DZ twin pairs was lower (correlation coefficient, $0.52 ; r^{2}=0.27, P<0.001$; Fig. 2). When the U.K. and Australian groups were analyzed separately, the MZ and DZ correlations were very similar to that of the whole group, with MZ correlations of 0.94 and 0.96 and $\mathrm{DZ}$ correlations of 0.53 and 0.52 , respectively (Table 1 ). The MZ and $\mathrm{DZ}$ correlations for the average CCT were also similar if the twins of different gender were analyzed separately (Table 2). The higher correlation of CCT in MZ twins implied a strong genetic influence on CCT.

Results of maximum-likelihood modeling for all subjects are summarized in Table 3. An AE model, combining both additive genetic effects and unique environment effects, provided the best-fitting model (with the lowest AIC). The heritability of CCT in this study was calculated to be 0.95 (95\% confidence interval $[\mathrm{CI}], 0.93-0.96)$, with the remaining variance $(0.05$, 95\% CI, $0.4-0.7)$ being attributable to environmental effects. These results did not significantly differ for the U.K. twins alone $\left(b^{2}=0.94,95 \%\right.$ CI $\left.0.91-0.96\right)$ or the Australian twins group $\left(b^{2}=0.95,95 \% \mathrm{CI}, 0.93-0.97\right)$. Dominant genetic effects and shared environmental effects were found not to be significant in this study.

\section{Discussion}

This study revealed CCT to be a highly heritable trait. With a heritability of 0.95 , genetic factors were the primary influence in the determination of CCT. Unique environmental effect (which included measurement error) contributed only 5\% of the variance. The measured heritability of CCT was substantially greater in our study than that calculated in the Greenland Eskimos study $(0.6-0.7) .{ }^{10}$ Factors that could contribute to this difference include differences in study design and/or greater measurement error in the Greenland Eskimos study, as it relied on optical determination of CCT. Alternatively, fundamental population differences may exist between the white twins in this study and the Greenland Eskimo population.

Given that our results demonstrated no significant difference in CCT between male and female subjects, or between the U.K. and Australian groups, combined analysis of the sample populations was justified. The mean CCT in the total study group (mean, $544.5 \mu \mathrm{m}$; 95\% CI, 472-617) was similar to that generated by a recent meta-analysis of normal white adult CCT, which found a mean of $535 \mu \mathrm{m}$ (95\% CI, 474-596. ${ }^{6}$ Twins have been found to be very similar to singletons for many complex traits, ${ }^{27}$ and the equal-environment assumption of twin studies is now widely accepted. ${ }^{28}$ The similarity of results between the U.K. and Australian twins, in conjunction with the

TABLE 2. Intraclass Correlations between MZ and DZ Twins of Different Gender

\begin{tabular}{|c|c|c|c|c|c|}
\hline & \multicolumn{2}{|c|}{$\mathbf{F} / \mathbf{F}$} & \multicolumn{2}{|c|}{$\mathbf{M} / \mathbf{M}$} & \multirow[b]{2}{*}{ Mixed } \\
\hline & MZ & $\mathbf{D Z}$ & MZ & $\mathbf{D Z}$ & \\
\hline Number (U.K./Australian) & $228(126 / 102)$ & $148(108 / 40)$ & $34(2 / 32)$ & $30(4 / 26)$ & $72(2 / 70)$ \\
\hline Mean age in years (SD) & $40.8(15)$ & $39.4(11)$ & $38.5(19)$ & $28.1(15)$ & $30.2(14)$ \\
\hline Mean CCT $(\mu \mathrm{m})(\mathrm{SD})$ & $\begin{array}{rr} & 40.2 \\
540.9(39) & \\
& 542.6\end{array}$ & $545.2(34)$ & $549(41)^{3}$ & $552.1(34)$ & $549.7(40)$ \\
\hline Intraclass correlation of mean CCT & 0.95 & 0.54 & 0.97 & 0.48 & 0.52 \\
\hline
\end{tabular}

F/F, same-sex female twin pairs; M/M, same-sex male twin pairs; Mixed, mixed-sex twin pairs. 
Figure 2. Comparison of CCT between twins 1 and 2 for $\mathrm{MZ}$ and $\mathrm{DZ}$ twin pairs.
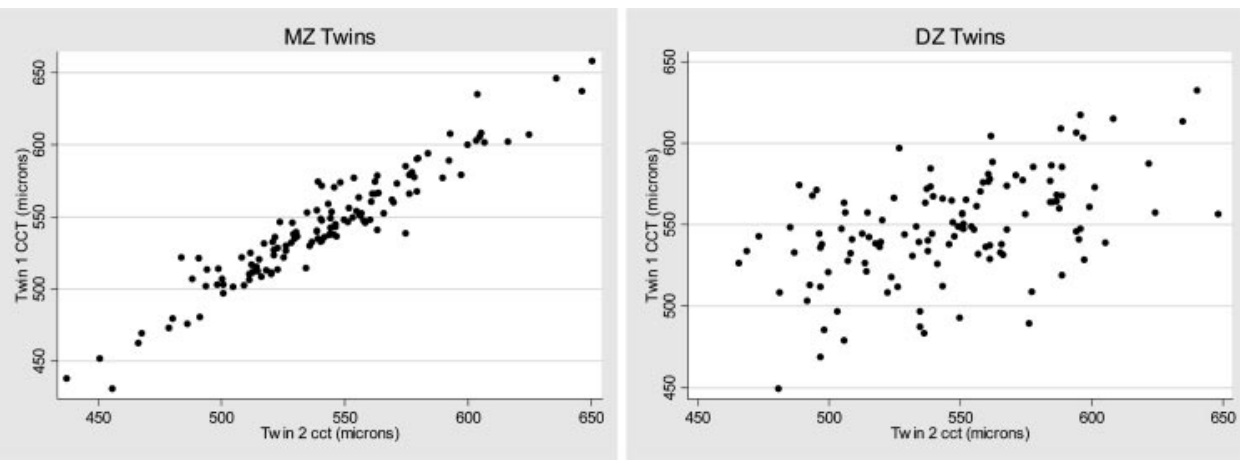

wide age range and open sampling method (population-based volunteer recruitment unselected for eye disease), may make our results generalizable to other white populations.

However, racial differences in CCT have recently been highlighted through several population studies. Nemesure et al. ${ }^{29}$ reported that CCT was thinner among the black Barbados population compared with the white Barbados population (mean $529.8 \pm 37.7 \mu \mathrm{m}$ vs. $545 \pm 45.7 \mu \mathrm{m}$ ). Mean CCT measurements among Hispanic patients were found to lie between those of African-Americans and a white population. ${ }^{29,30}$ However, Cho and $\mathrm{Lam}^{31}$ suggested that the Chinese population has the highest mean CCT $(574.5 \mu \mathrm{m})$. Given the difference in CCT between racial groups, our results may not be entirely applicable to those in other populations.

Our data showed a negative association of CCT with age, of marginal significance (correlation coefficient, $-0.09 ; P=$ 0.048). Some studies examining the impact of age on CCT have reported no significant association, especially among white populations, ${ }^{30,32-34}$ whereas others have found a definite inverse association for nonwhites. ${ }^{29,35-37}$ There was no correlation of CCT with refractive error in this study $(P=0.47)$. Other studies examining this relationship have reported mixed results. In a prospective multicenter study of 896 eyes, Price et al. ${ }^{34}$ found no correlation of CCT with refraction or axial length. Other investigators found CCT to be thinner in myopes. ${ }^{34,38}$

Although the genes determining CCT in the normal population have not been identified, there are many potential candidate genes including those that are associated with diseases having thick or thin CCT phenotypes. ${ }^{11-18}$ Using a combination of genome-wide scan and multipoint linkage analysis, a sibling pair study of the DZ twins from this sample population could identify loci of potential importance in CCT.

In a complex heterogeneous disease such as glaucoma, the study of an intermediate phenotype or significant confounder such as CCT may aid in the identification of glaucoma-related genes. Searching for POAG genes other than myocilin, optineurin, and WDR36 has been difficult. Linkage studies, even with large families, have met with limited success as a result of

TABLE 3. Maximum-Likelihood Modeling of Mean CCT

\begin{tabular}{lrccr}
\hline Model & $\boldsymbol{\chi}^{2}$ & DF & $\boldsymbol{P}$ & \multicolumn{1}{c}{ AIC } \\
\hline ADE & 8.359 & 3 & 0.039 & 2.359 \\
ACE & 7.657 & 3 & 0.054 & 1.657 \\
AE & 8.359 & 4 & 0.079 & 0.359 \\
CE & 135.883 & 4 & 0.000 & 127.883 \\
E & 343.977 & 5 & 0.000 & 333.977 \\
\hline
\end{tabular}

A, additive genetic; D, dominant genetic; C, common environment; E, unique environment; $\chi^{2}$, chi-square goodness of fit statistic; DF, change in degrees of freedom between submodel and full model; $P$, probability that $\Delta \chi^{2}$ is zero; AIC, Aikake Information Criterion. genetic heterogeneity and the age-dependent phenotype. Sibpair studies have yielded a large number of genetic regions of interest but with uncertain significance. Determining the most heritable ocular structures or physiological processes will allow recategorization of the glaucoma population and the potential for regression-based linkage approaches to help dissect this complex phenotype, as has been performed for other complex traits. ${ }^{39}$ Our preliminary data suggest that CCT is more heritable than optic disc cup area (0.86) (Poulsen JL et al. IOVS 2005; 46:ARVO E-Abstract 1092), refraction (0.85), ${ }^{40}$ and IOP (0.7) (MacKinnon J et al. IOVS 2004;45:ARVO E-Abstract 4390). We have demonstrated that genetic effects play an important role in CCT, with an estimated heritability of 0.95 . These results may lead to the discovery of further glaucomarelated genes.

\section{Acknowledgments}

The authors thank all the twin volunteers; Shayne Brown, Lisa Kearns, and Lindsey Scotter for clinical assistance; Nick Martin's Brisbane Adolescent Twin Study and the Australian Twin Registry for assistance with subject recruitment, and Alison MacKenzie, Ann Eldridge, and Marlene Grace for assistance with the Brisbane twins.

\section{References}

1. Stone EM, Fingert JH, Alward WL, et al. Identification of a gene that causes primary open angle glaucoma. Science. 1997;275:668-670.

2. Rezaie T, Child A, Hitchings R, et al. Adult-onset primary openangle glaucoma caused by mutations in optineurin. Science. 2002; 295:1077-1079.

3. Monemi S, Spaeth G, Dasilva A, et al. Identification of a novel adult-onset primary open-angle glaucoma (POAG) gene on 5q22.1. Hum Mol Genet. 2005;14:725-733.

4. Beck AD. Review of recent publications of the Advanced Glaucoma Intervention Study. Curr Opin Opbthalmol. 2003;14:83-85.

5. Ehlers N, Bramsen T, Sperling S. Applanation tonometry and central corneal thickness. Acta Opbthalmol (Copenb). 1975;53:3443.

6. Doughty MJ, Zaman ML. Human corneal thickness and its impact on intraocular pressure measures: a review and meta-analysis approach. Surv Opbthalmol. 2000;44:367-408.

7. Brandt JD, Beiser JA, Kass MA, Gordon MO. Central corneal thickness in the Ocular Hypertension Treatment Study (OHTS). $O p b$ thalmology. 2001;108:1779-1788.

8. Herndon LW, Weizer JS, Stinnett SS. Central corneal thickness as a risk factor for advanced glaucoma damage. Arch Opbthalmol. 2004;122:17-21.

9. Medeiros FA, Sample PA, Zangwill LM, Bowd C, Aihara M, Weinreb $\mathrm{RN}$. Corneal thickness as a risk factor for visual field loss in patients with preperimetric glaucomatous optic neuropathy. $A m \mathrm{~J} O p b$ thalmol. 2003;136:805-813.

10. Alsbirk PH. Corneal thickness. II. Environmental and genetic factors. Acta Ophthalmol (Copenb). 1978;56:105-113. 
11. Henriques MJ, Vessani RM, Reis FA, de Almeida GV, Betinjane AJ, Susanna R Jr. Corneal thickness in congenital glaucoma. J Glaucoma. 2004;13:185-188.

12. Evereklioglu C, Madenci E, Bayazit YA, Yilmaz K, Balat A, Bekir NA. Central corneal thickness is lower in osteogenesis imperfecta and negatively correlates with the presence of blue sclera. Ophthalmic Pbysiol Opt. 2002;22:511-515.

13. Evereklioglu C, Yilmaz K, Bekir NA. Decreased central corneal thickness in children with Down syndrome. J Pediatr Opbthalmol Strabismus. 2002;39:274-277.

14. Meire FM, Delleman JW. Biometry in X linked megalocornea: pathognomonic findings. Br J Ophthalmol. 1994;78:781-785.

15. Patel S, McLaughlin JM. Effects of central corneal thickness on measurement of intra-ocular pressure in keratoconus and postkeratoplasty. Opbthalmic Physiol Opt. 1999;19:236-241.

16. Sultan G, Baudouin C, Auzerie O, De Saint JM, Goldschild M, Pisella PJ. Cornea in Marfan disease: orbscan and in vivo confocal microscopy analysis. Invest Ophthalmol Vis Sci. 2002;43:1757-1764.

17. Pesudovs K. Orbscan mapping in Ehlers-Danlos syndrome. J Cataract Refract Surg. 2004;30:1795-1798.

18. Brandt JD, Casuso LA, Budenz DL. Markedly increased central corneal thickness: an unrecognized finding in congenital aniridia. Am J Opbthalmol. 2004;137:348-350.

19. Martin N, Boomsma D, Machin G. A twin-pronged attack on complex traits. Nat Genet. 1997;17:387-392.

20. Wright MJ, Martin NG. Brisbane Adolescent Twin Study: outline of study methods and research projects. Aust J Psychol. 2004;56:6578 .

21. Hopper JL. The Australian Twin Registry. Twin Res. 2002;5:329336.

22. Zhu G, Evans DM, Duffy DL, et al. A genome scan for eye color in 502 twin families: most variation is due to a QTL on chromosome 15q. Twin Res. 2004;7:197-210.

23. Martin NG, Martin PG. The inheritance of scholastic abilities in a sample of twins. I. Ascertainments of the sample and diagnosis of zygosity. Ann Hum Genet. 1975;39:213-218.

24. Peeters H, Van Gestel S, Vlietinck R, et al. Validation of a telephone zygosity questionnaire in twins of known zygosity. Behav Genet. 1998;28:159-163.

25. Spitz E, Moutier R, Reed T, et al. Comparative diagnoses of twin zygosity by SSLP variant analysis, questionnaire, and dermatoglyphic analysis. Behav Genet. 1996;26:55-63.

26. Neale MC, Boker SM, Xie G, Maes HH. Mx: Statistical Modeling. 6th ed. Richmond, VA: Medical College of Virginia, Department of Psychiatry; 2002:1-217.
27. Andrew T, Hart DJ, Snieder H, de Lange M, Spector TD, MacGregor AJ. Are twins and singletons comparable?-a study of diseaserelated and lifestyle characteristics in adult women. Twin Res. $2001 ; 4: 464-477$.

28. Kyvic KO. Generalisability and assumptions of twin studies. In: Spector TD, Sneider H, MacGregor AJ, eds. Advances in Twin and Sib-Pair Analysis. London: Greenwich Medical Media; 2000; 2004; 67.7 .

29. Nemesure B, Wu SY, Hennis A, Leske MC. Corneal thickness and intraocular pressure in the Barbados eye studies. Arch Opbthalmol. 2003;121:240-244.

30. Shimmyo M, Ross AJ, Moy A, Mostafavi R. Intraocular pressure, Goldmann applanation tension, corneal thickness, and corneal curvature in Caucasians, Asians, Hispanics, and African Americans. Am J Opbthalmol. 2003;136:603-613.

31. Cho P, Lam C. Factors affecting the central corneal thickness of Hong Kong-Chinese. Curr Eye Res. 1999;18:368-374

32. Wolfs RC, Klaver CC, Vingerling JR, Grobbee DE, Hofman A, de Jong PT. Distribution of central corneal thickness and its association with intraocular pressure: The Rotterdam Study. $A m \mathrm{~J} O \mathrm{Ob}$ thalmol. 1997;123:767-772.

33. Eysteinsson T, Jonasson F, Sasaki H, et al. Central corneal thickness, radius of the corneal curvature and intraocular pressure in normal subjects using non-contact techniques: the Reykjavik Eye Study. Acta Opbthalmol Scand. 2002;80:11-15.

34. Price FW Jr, Koller DL, Price MO. Central corneal pachymetry in patients undergoing laser in situ keratomileusis. Opbthalmology. 1999; 106:2216-2220.

35. Foster PJ, Baasanhu J, Alsbirk PH, Munkhbayar D, Uranchimeg D, Johnson GJ. Central corneal thickness and intraocular pressure in a Mongolian population. Ophthalmology. 1998;105:969-973.

36. Alsbirk PH. Corneal thickness. I. Age variation, sex difference and oculometric correlations. Acta Opbthalmol (Copenb). 1978;56: 95-104.

37. Nishiyama K, Urakawa Y, Okubo H. Aging changes in central corneal thickness. Nippon Ganka Gakkai Zasshi. 1987;91:415419.

38. Chang SW, Tsai IL, Hu FR, Lin LL, Shih YF. The cornea in young myopic adults. Br J Opbthalmol. 2001;85:916-920.

39. Craig JE, Rochette J, Fisher CA, et al. Dissecting the loci controlling fetal haemoglobin production on chromosomes $11 \mathrm{p}$ and $6 \mathrm{q}$ by the regressive approach. Nat Genet. 1996;12:58-64.

40. Hammond C, Snieder H, Gilbert C, et al. Genes and environment in refractive error: the twin eye study. Invest Ophthalmol Vis Sci. $2001 ; 42: 1232-1236$ 